\title{
LA CLÁUSULA COMO MENSAJE: ANÁLISIS CONTRASTIVO DE LA SECCIÓN SUCESOS EN LA TITULACIÓN PERIODÍSTICA COSTARRICENSE
}

\author{
The clause as message: contrastive analysis of Costa Rican \\ headlines related to accidents and crime reports
}

Ericka Vargas Castro*

\begin{abstract}
RESUMEN
En el presente artículo se estudia la estructura de la cláusula como mensaje, de acuerdo con los presupuestos de Halliday (2004), en titulares de la sección Sucesos de tres periódicos costarricenses: La Nación, La Prensa Libre y La Extra, con el fin de indagar si la creatividad lingüística en periodismo alcanza el nivel sintáctico. Los resultados muestran que en La Nación y en La Prensa Libre se prefiere, de forma contundente, el uso de Temas no marcados, pues esta organización permite que la noticia sea más fácil de leer y procesar. El diario que presentó más cantidad de titulares con Tema marcado fue La Extra, en donde existe una mayor tendencia a optar por una distribución no canónica de los elementos para particularizar el suceso, hacerlo más atractivo al lector y así cumplir con el objetivo de informar y entretener.

Palabras clave: Halliday, metafunción textual, cláusula como mensaje, titulación periodística, análisis del discurso.
\end{abstract}

\begin{abstract}
In this paper we study the structure of the clause as a message according to Halliday (2004), in headlines related to accidents and crime reports of three Costa Rican newspapers: La Nación, La Prensa Libre and La Extra in order to assess the degree in which linguistic creativity in journalistic discourse reaches the syntactic level. The results show a preference for unmarked Theme clauses in La Nación and La Prensa Libre, for this organization is easier to read and process. It was in La Extra where more headlines containing marked Themes were used. This fact demonstrates that in La Extra there is a stronger tendency to choose an alternative distribution of the elements in order to particularize the event, and present it in a more appealing form to the reader, which contributes to meet its communicative objectives: informing an entertaining.

Keywords: Halliday, textual metafunction, clause as a message, newspaper headlines, discourse analysis.
\end{abstract}

* Universidad de Costa Rica, Profesora, Escuela de Filología, Lingüística y Literatura. Costa Rica.

Correo electrónico: vargasc.ericka@gmail.com

Recepción:20/4/16. Aceptación: 21/4/16. 


\section{Introducción}

En la gramática sistémico-funcional, se considera que el lenguaje es un instrumento que le permite al ser humano representar y organizar el mundo, así como establecer y mantener relaciones sociales. En primera instancia, en su función cognitiva, posibilita segmentar el continuum de la realidad para codificarla en signos lingüísticos. Adicionalmente, la gramática viabiliza la proyección de aconteceres desde varias perspectivas, por cuanto la forma final que adquiere el enunciado puede variar según la interpretación de los eventos, ideologías y objetivos comunicativos particulares.

Para Halliday (2004: 64), el carácter de una cláusula en tanto mensaje surge cuando el hablante elige una de las posibilidades de organización de los elementos que le brinda el sistema, debido a que dicha opción le permitirá presentar su enunciado como discursivamente relevante. Los sistemas de TEMA e INFORMACIÓN son los que otorgan el estatus textual al organizar la cláusula desde un punto de partida pertinente en el contexto comunicativo que la origina, hacia el establecimiento de algún aspecto novedoso, indispensable para la progresión temática.

En la presente investigación, se aplican los presupuestos teóricos acerca de la metafunción textual expuestos por Halliday (2004) a un corpus conformado por titulares extraídos de los periódicos costarricenses La Nación, La Prensa Libre y La Extra con el propósito de indagar sobre el paso de la cláusula desde un hecho meramente representativo, hacia la forma final que se le ha asignado según las necesidades comunicativas particulares del medio de comunicación escrita.

\section{Estado de la cuestión}

\subsection{Los titulares: definición e importancia}

Hernando (2000: 17) identifica tres partes fundamentales en la noticia: el título o titular, elemento obligatorio que destaca tipográficamente, y transmite, en una forma compacta, los significados que se desean dar a conocer (de manera optativa puede incluir un antetítulo o un subtítulo); el lead o entrada, párrafo inicial que busca dar a conocer lo sustancial de la noticia y responde a las interrogantes de ¿qué?, ¿quién?, ¿cuándo?, ¿dónde?, ¿por qué?, ¿cómo?' en torno a ese acontecimiento destacado; y el cuerpo de la noticia, que complementa la información que aparece tanto en el titular como en el lead.

De entre estos elementos constitutivos, el titular es el más importante, ya que cumple con la función fática del lenguaje según la teoría de Jakobson (1984: 356), es decir, inicia el acto comunicativo. Alarcos-Llorach (citado por Hernando 2000: 22-25) identifica en él las funciones de sobresalir, indicar el contenido y seducir al receptor, mientras que Núñez-Ladeveze (1979: 242-244) destaca la conexión que establece entre el mundo exterior, los textos preexistentes y el nuevo producto, que además circunscribe el contenido que se deberá desarrollar a partir de premisas de pertinencia. Por su parte, Van Dijk (1996: 55) afirma que el titular es una parte decisiva porque guía la interpretación de la noticia en cuanto macroestructura semántica que indica de antemano lo que se va a encontrar dentro del texto y cómo debe ser leído. Finalmente, Sánchez-Sánchez (1990: 177-180) señala que estudiando la configuración lingüística interna de los titulares se pueden develar características del tono del texto que conllevan implicaciones en relación con la forma en que el diario busca proyectarse a sí mismo.

\subsection{Investigaciones previas sobre titulares}

Debido a su relevancia social, el discurso periodístico y, en particular, los titulares han sido objeto de múltiples estudios desde variadas perspectivas. A nivel morfológico, Nadal (2008: 175) identifica en titulares mexicanos el uso extendido de la nominalización deverbal, proceso de derivación de sustantivos a partir de verbos. Este autor afirma que el uso de determinadas estructuras gramaticales es significativa en tanto responde a motivaciones ideológicas que 
orientan la interpretación del enunciado; por ejemplo, el empleo del sustantivo divulgación, derivado de la raíz verbal divulgar, da a conocer acciones y omite la identidad del agente, recurso particularmente útil si esta se desconoce o si se prefiere no revelarla.

Cuvardic y Vargas (2010) rastrearon en los periódicos costarricenses La Nación y La Extra los procedimientos de creatividad lingüística propuestos por Guerrero (2007), dentro de los que cabe mencionar la sufijación y prefijación, neologismos originados por metáforas o eufemismos, cruces léxicos, siglación y el uso de frases hechas y expresiones consagradas. Mientras que Guerrero (2007) señaló la prefijación como el recurso más usado en prensa española, en los diarios costarricenses destacó la nominalización, en el caso de $L a$ Nación, y el uso de metáforas y de léxico popular en La Extra. Asimismo, Vargas (2015) identificó como recurso estilístico particular de la sección Deportes de La Extra el énfasis en diversas funciones del lenguaje de Jakobson, no solo fática y referencial, sino también la emotiva, la conativa o la metalingüística implícita, con el fin de atraer al lector e interactuar con el contenido del mensaje.

A nivel sintáctico, destaca el estudio de Franco y Casanova (2006), quienes indagaron sobre las funciones de Tema y Rema en los titulares y leads de la prensa venezolana, a partir de las premisas teóricas de Gutiérrez Ordóñez (2000). Los autores consideran que las tres funciones lingüísticas (la sintáctica, la semántica y la informativa) son cruciales en el discurso periodístico a la hora de estructurar el titular y la noticia, y sostienen que los mecanismos de focalización son claves en el ámbito informativo. Además, se asignó el máximo grado de cohesión textual a los casos en los cuales la estructura temática del titular y del lead coincide. Si se rompe esta relación, el discurso pierde eficacia y pertinencia.

\section{El corpus estudiado}

Los criterios para seleccionar los periódicos con los que se trabajó obedecen a la distinción entre diarios de referencia y "clases populares" utilizada por autores como Sunkel (2002) y Samiolo (2008: 43-50). Estos investigadores reconocen en los diarios de referencia características como uso de vocabulario estándar, transmisión de noticias duras -serias, en oposición a temas triviales-y con alta credibilidad. Los diarios intermedios no poseen estándares de redacción tan estrictos ni rigurosos y combinan noticias duras con triviales. Por último, los diarios de "las clases populares" presentan un texto noticioso más segmentado y sencillo que busca tanto informar como entretener al lector. Tienden a personalizar la información y esto se ve reflejado en el uso del lenguaje informal -o lenguaje popular como lo designa Sunkel (2002: 109)- con vocabulario cotidiano, emotivo y expresiones idiomáticas propias de la comunidad de habla. Bajo esta óptica, se seleccionó La Nación como representante de los periódicos de referencia, $L a$ Prensa Libre como intermedio, y La Extra como diario de "las clases populares".

En esta investigación, se emplearán las premisas de la metafunción textual de Halliday (2004) con el fin de analizar la organización Tema-Rema en un total de 405 titulares de la sección Sucesos (135 títulos por tipo de diario), recolectados durante el mes de marzo del año 2011. Para esto, se identificarán y contabilizarán los desplazamientos sintácticos, pues muestran la perspectiva desde la cual se aborda el acontecimiento y, a continuación, se comentarán posibles razones por las cuales la organización de los elementos asignada a la cláusula se ha considerado como la más pertinente para insertar al titular en su contexto social y captar al público meta. En principio, la selección temática varía según el tipo de diario y la sección a la que pertenece el titular.

\section{Marco teórico}

\subsection{Las metafunciones}

Halliday (2004: 29) afirma que las funciones básicas del lenguaje giran en torno 
a la necesidad de construir la experiencia humana -poder transformarla en significados comunicables- así como habilitar las relaciones sociales. Esto se manifiesta en la cláusula, la cual tiene la propiedad de transmitir significados de tres clases diferentes que obedecen a funciones específicas, cada una de las cuales recibe el nombre de metafunción. La metafunción es aquella configuración funcional que proyecta los usos del lenguaje más trascendentales facilitados por el sistema semántico. Halliday ha distinguido tres de ellas: la ideacional, la interpersonal y la textual.

La metafunción ideacional es la que permite representar, por medio del lenguaje, los fenómenos del entorno y las experiencias, tanto individuales como culturales del ser humano. Si bien es cierto la realidad es un continuum, para poder codificarla lingüísticamente, es necesario segmentarla, hecho que origina las categorías de Participantes, Procesos y Circunstancias. Los Procesos son los elementos primordiales que transmiten el flujo de eventos con los cuales los Participantes se relacionarán directamente. A estos se les puede incorporar Circunstancias que especifiquen el tiempo, lugar, manera y causa, entre otros.

La metafunción interpersonal es la que posibilita las relaciones humanas al organizar el lenguaje como un evento interactivo que involucra al hablante y a su audiencia en actos de habla, los cuales comprenden dos grandes subdivisiones: dar y pedir, ya sea bienes y servicios o información. De ahí devienen las funciones de ofrecimiento, orden, declaración y pregunta, con sus respuestas respectivas, sean aquellas que cumplen con las expectativas o las marcadas por contradecirlas. El Modo, entonces, es aquella selección hecha por el hablante según el contexto y el papel que este implica para el oyente y está compuesto por el Sujeto y el Finito. El Sujeto marca aquello sobre lo cual una proposición puede ser afirmada o negada, o sea que a partir de él una aseveración adquiere validez. Por su parte, el Finito es el que circunscribe la realización deíctica de la cláusula, es decir, especifica el aquí y el ahora relacionando la proposición con su contexto. El resto de la cláusula lo compone el Residuo, el cual consiste de Predicador, Complemento y Adjunto.

Por último, la metafunción textual se centra en la construcción del texto y la forma en que se van conectando los elementos para lograr una inserción efectiva de la cláusula en el contexto al hacerla informativamente relevante. $\mathrm{Su}$ estatus es el de la cláusula como mensaje. Es el lenguaje a nivel operativo que habilita las dos metafunciones anteriores (Halliday 1986: 149).

\subsection{La metafunción textual}

El sistema TEMA, que rige la metafunción textual, posee dos elementos constitutivos: el Tema y el Rema. Esta configuración se implica mutuamente, ya que cuando una parte es enunciada como Tema (y definida como tal), se combina con el Rema (el resto de los elementos en ella) y la unión de ambas permite construir el mensaje de manera que exista una conexión semántico-lingüística de elementos para que así la cláusula tenga "some form of organization whereby it fits in with, and contributes to the flow of discourse" (Halliday 2004: 64). La sucesión de las cláusulas configuran el texto $\mathrm{y}$, por ende, deberán promover la continuidad discursiva. La metafunción textual hace factible acercarse a los mecanismos que los hablantes utilizan para introducir sus pensamientos y muestra la forma en que el lenguaje establece correspondencias consigo mismo y con el contexto situacional.

\subsection{Tema marcado y no marcado en español}

Según Halliday (2004: 72), la definición de Tema marcado y no marcado dependerá de la selección de MODO de la cláusula mayor, el cual puede ser indicativo (en donde se despliegan las opciones declarativa o interrogativa y esta última contiene las posibilidades de polar o de contenido) o imperativo, que no presenta subdivisiones. 
En este trabajo interesa únicamente la opción indicativa declarativa, por ser el único modo empleado en los títulos del corpus.

La forma no marcada es aquella en la cual el Tema y el Sujeto son el mismo, ya que "The Subject is the element that is chosen as Theme unless there is a good reason for choosing something else" (Halliday 2004: 73). Este Sujeto inicial que funciona como Tema puede realizarse con un pronombre personal o grupos nominales. En español, por ser una lengua en la cual hay marcación de persona en el verbo, se puede elidir el Sujeto cuando es posible deducirlo a partir del contexto comunicativo (pronombres deícticos) o cuando ya ha sido manifestado previamente (en el caso de terceras personas). Este hecho hace que el Predicador pueda ser el punto de partida no marcado:

\section{(1) Vine a verte}

El uso del pronombre personal de primera persona como elemento inicial de la cláusula implica énfasis o contraste.

(2) Yo no fui

Los grupos nominales, que incluyen tanto sustantivos comunes como propios, conforman otra posibilidad para el Tema no marcado y se utilizan para referirse a los otros, aquellos que no están presentes durante el acto comunicativo, o que son designados por primera vez.

La selección marcada emerge al haber un desplazamiento de Adjuntos (ya sea con adverbios como ayer o frases preposicionales como por la tarde) o de Complementos, es decir, un grupo nominal que no esté funcionando como Sujeto, al inicio del enunciado. En español, hay cláusulas que inician con Complemento realizado por un pronombre átono y son no marcadas, como ocurre en:

(3) Carlos me regaló una cartera. La trajo de Brasil.

En este ejemplo, en la segunda cláusula se ha elidido el sujeto Carlos y se presenta al Complemento cartera como información ya conocida, por lo que se puede hacer referencia a él utilizando un pronombre. Esta es la posición que la lengua otorga a dicho pronombre $y$, en consecuencia, es no marcado.

Los casos en los que el complemento se realiza por un grupo nominal y cumple la función de Tema sí se consideran marcados. Así, en una oración como:

\section{(4) Una muñeca me compré.}

El hablante ha decidido enfatizar el Complemento tematizándolo, sin dejar de lado su participación en el evento codificándose a sí mismo en la conjugación del verbo y en el Complemento Indirecto $(\mathrm{CI})$. Este procedimiento obliga a establecer una doble marca del Complemento, una con la preposición a + sustantivo o grupo nominal y otra como pronombre átono:

(5) A Juan lo vi en el mercado.

(6) A Cristina le di un premio.

Además, un Predicador se considerará como marcado en caso de que se utilice como punto de partida en cláusulas receptivas (o pasivas, en términos de la Real Academia Española) si, posteriormente, se ha incorporado el Sujeto.

Por otra parte, las nominalizaciones son estructuras definidas por Halliday (2004: 69) como cualquier elemento o conjunto de elementos que funcionan como grupo nominal en la cláusula. En los ejemplos proporcionados por este autor, se trata de cláusulas bajadas a nivel de grupo. Estas estructuras desempeñan una función sintáctica dentro de la clausula principal y pueden ser Temas no marcados en oraciones ecuativas cuando cumplen la función de Sujeto, mientras que si aparecen como Complemento en una cláusula que no sea ecuativa (o sea, una cuyo verbo principal no sea el verbo ser) se consideran marcadas:

(7) Lo que le dieron a María fue un gran beso (Nominalización no marcada).

(8) Lo que no se va a comer no lo toque (Nominalización marcada en función de Complemento). 


\section{Resultados}

Los Temas no marcados mostraron la siguiente distribución:

Gráfico 1.

Resultados de Temas no marcados en Sucesos de La Nación, La Prensa Libre y La Extra.

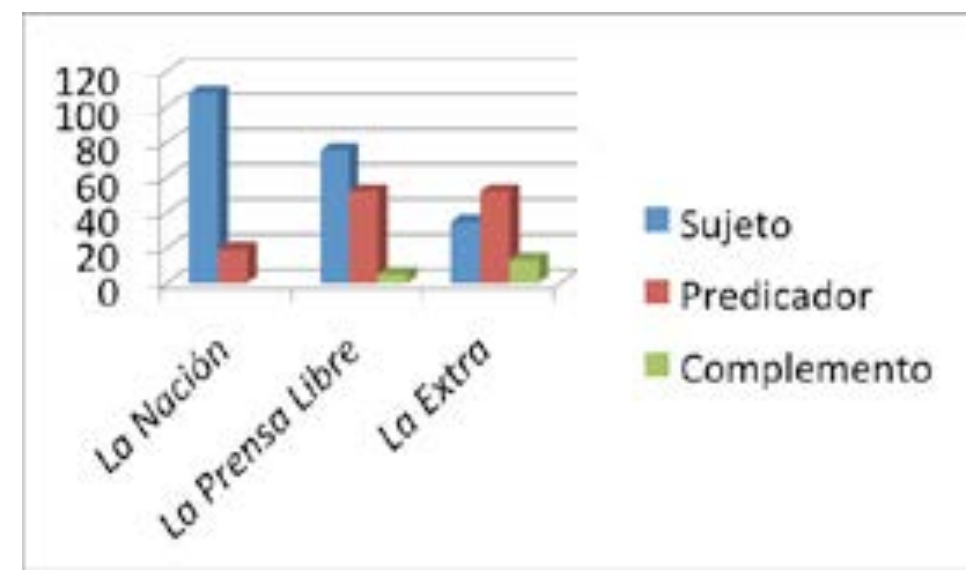

La Nación es el periódico en el que se emplearon la mayor cantidad de titulares no marcados con sujeto como punto de partida, con un total de 108 ejemplos, mientras que en La Prensa Libre se utilizó en 75 casos y en La Extra la cantidad se reduce significativamente, pues solo se registraron 35 títulos estructurados de esa forma.

Los sujetos como Temas pueden estar ejerciendo la función ideacional de Meta o de Actor, como se ilustra en los siguientes casos:

(9) Policía mata de balazo a sujeto que hirió con machete a oficial (LN, 4.03.2011: 22A)

(10) Desconocidos roban $\phi 44$ millones de cajero automático en San Carlos (LN, 3.03.2011: 17A)

(11) Otro hombre asesinado por disputa de pandillas (LN, 11.03.2011: 17A)

En estos ejemplos, los Sujetos codifican entidades que se pueden inferir según el tipo de noticia (o sea información en torno a crímenes): policías $-\mathrm{o}$ instituciones como el OIJ (Organismo de Investigación Judicial)-, víctimas y victimarios. El Sujeto como punto de partida se registró en cláusulas operativas -en las instancias en las que el Sujeto y el Actor son el mismo, como sucede en los ejemplos (9) y (10)- y en receptivas, en el caso de que el Sujeto cumpla la función ideacional de Meta, como ocurre en (11), selección preferible cuando el $\mathrm{CD}$ de la cláusula operativa tiene un alto grado de vinculación con el contexto y con la situación comunicativa. En (11) se ha utilizado un tipo de oración conocida por la Real Academia Española como pasiva perifrástica (RAE 2010: 775), pero el auxiliar ser se ha elidido, procedimiento típico en titulación periodística por criterios de economía de espacio. En este caso, se da a conocer lo ocurrido al elemento seleccionado como punto de partida (otro hombre), pero se 
omiten detalles en relación con el Actor, pues no se adjunta el complemento agente.

En La Prensa Libre y La Extra, se tienden a emplear Sujetos cuya carga semántica despierte empatía:

(12) Niña de cinco años muere ahogada al caer a rio (LPL, 19.03.2011: 19)

(13) "La pelona" lo veló 10 días para llevárselo (LE, 19.03.2011: 10)

En el ejemplo (12), la alusión a una niña de cinco años tiene el potencial de hacer que el lector se identifique con la víctima y se interese por saber qué le ocurrió, por cuanto su combinación con el Rema (muere ahogada al caer a río) podría despertar sentimientos de solidaridad ante la pérdida. Los juegos semánticos aparecen en (13), donde la expresión popular la pelona hace referencia a la muerte, la cual es personificada para crear un matiz de suspenso. Según Lakoff y Johnson (2003: 33), las personificaciones permiten comprender una serie de experiencias que involucran conceptos inanimados y abstractos en virtud de motivaciones humanas. En (13) se compara a la muerte con un criminal que espía a sus víctimas hasta que, al final, las acorrala y aniquila. El asignarle este tipo de rasgos posibilita comprenderla en su proceder silencioso y letal. Por lo tanto, este titular, cuyo Tema parte de un término de corte popular, transita hacia un Rema que proyecta un fallecimiento como un hecho premeditado e inexorable.

Otra tendencia frecuente en los títulos periodísticos estructurados a partir del Sujeto es que el grupo nominal esté compuesto por una Cabeza que designa alguna ocupación:

(14) Bodeguero asesinado forcejeó con asaltante (LPL, 3.03.2011: 18)

(15) Pipero le corta cuello a pareja (LE, 9.03.2011: 9)

En estos casos, se individualiza un Participante -ya sea la Meta como en (14) o el Actor como en (15)-, al designar el tipo de trabajo que realiza, lo cual se efectúa por medio del sufijo no apreciativo nominal $-e r$, de uso frecuente para la nomenclatura de empleos. En el ejemplo (15), al sustantivo pipa -palabra utilizada en Costa Rica para designar a un coco verde - se le agrega el sufijo para hacer mención a la labor de vender pipas. El procedimiento resulta efectivo para organizar el enunciado a partir de labores que forman parte de la cotidianeidad costarricense.

El segundo tipo de Tema no marcado que más se utilizó fue el Predicador. Este se empleó en un total de 19 ejemplos de La Nación. Su uso aumenta en La Prensa Libre y en La Extra, con un total de 52 casos para cada diario. En $L a$ Extra, el Predicador como punto de partida llega incluso a superar la cantidad de Sujetos como Tema. Los Predicadores especifican el tipo de Proceso (acciones, eventos, relaciones, etc.) y, en Sucesos, estos se realizan por medio de verbos que tienden a estar vinculados, semánticamente, con crímenes y acciones violentas (como matar, asaltar, amordazar). Por ende, si se toma en consideración el hecho de que La Extra coincide con el formato sensacionalista tanto por el color rojo en sus titulares -el cual remite a la sangre- como por la selección e incorporación de imágenes de tono violento junto a la noticia, colocar el titular a partir del Predicador resulta ser el mecanismo lingüístico más eficiente para reforzar la función que los otros dos elementos visuales (las imágenes y el color) cumplen: intensificar el efecto que lo ocurrido pueda producir en el lector, como se muestra en los siguientes casos:

(16) Matan embarazada de machetazo en la nuca (LE, 14.03.2011: 13)

(17) Agarró a su ex a puñaladas (LE, 30.03.2011: 11)

En el ejemplo (16) el Predicador adquiere tematicidad por medio de la selección sintáctica de la impersonalidad. No interesa revelar el elemento sobre el cual recae la responsabilidad modal, sino que más bien los objetivos comunicativos se centran en los aspectos claves que tienen el potencial de crear sensación y de intensificar lo violento del acontecimiento; dicha cualidad está en el verbo seleccionado'. 
En este caso, la persona afectada era una mujer embarazada (pero se elide la palabra mujer por considerarse sobrentendida) y su estado tiene la capacidad de acrecentar lo siniestro del crimen (ya que no fue una, sino dos víctimas). En el ejemplo (17), se saca provecho de la propiedad de elisión del Sujeto para centrarse en el Predicador que se realiza por medio de un verbo (agarrar), el cual, en el español popular, se utiliza para introducir una acción súbita y sorprendente, que solo llega a comprenderse en su totalidad aunado al régimen preposicional (a puñaladas).

La presencia del Predicador como punto de partida también puede deberse a un interés en destacar las acciones ocurridas:

(18) Investigan hallazgo de cráneo (LE, 3.03.2011: 12)

(19) Huye de tránsito y aplasta frutero (LE, 22.3.2011: 8)

Así, en el titular $(18)^{2}$, se asume que, a nivel nacional, el OIJ (Organismo de Investigación Judicial) es el encargado de llevar a cabo las investigaciones en relación con crímenes y con hallazgos de restos humanos, por lo que su mención resulta innecesaria. En el ejemplo (19), cuyo antetítulo es en apariencia iba bajo los efectos del alcohol, Puriscal, pueden deducirse algunos rasgos generales sobre el Sujeto, como el hecho de que se trata de un conductor; sin embargo, se prefiere seleccionar el Predicador como Tema no marcado por ser el elemento que resulta más impactante $\mathrm{y}$, posteriormente, se revelan los detalles en el cuerpo de la noticia, entre ellos el nombre del criminal. Estos ejemplos muestran cómo la representación ideacional de lo sucedido se puede modificar por medio de selecciones sintácticas como las construcciones impersonales (18) o elisiones (19) para asignar a la cláusula una forma que satisfaga las intenciones comunicativas del hablante y del oyente y que evite la mención de aquello que se considere innecesario, poco relevante, o que, intencionalmente, prefiere dejarse de lado.

Otra tendencia estilística en Sucesos es el uso recurrente del Predicador caer como Tema en su acepción de ser capturado:
(20) Cae pandilla de güilas que atemorizaba Sagrada (LE, 9.03.2011: 11)

(21) Cae conductor sospechoso de matar niña en Cariari (LPL, 5.03.2011: 18)

(22) Cae con 182 gramos de mota en vagina (LE, 21.03.2011: 28)

En los ejemplos (20) y (21) hay una posposición del Sujeto, la cual es frecuente en oraciones intransitivas. En (22) se opta por una elisión Sujeto pues este, por sí mismo, no se considera trascendente, sino que lo llamativo del titular está concentrado en el Adjunto ubicado al final de la cláusula: la posesión de droga en una parte del cuerpo humano cuya mención es socialmente tabuizada. Es interesante notar que, tanto en (20) como en (22), lo novedoso se inscribe en términos lingüísticos dentro de la comunidad de habla para la cual la noticia va dirigida por medio de la utilización del léxico popular: güilas -niños o adolescentes- y mota -marihuana- respectivamente, así como por el acortamiento del nombre propio del lugar que estaba siendo atacado por la banda: Sagrada Familia en (20).

En La Nación y en La Prensa Libre, también se registró el Predicador como punto de partida en cláusulas receptivas:

(23) Condenado a 15 años de prisión por secuestro (LN, 23.03.2011: 17A) ${ }^{3}$

(24) Baleado en la cabeza (LPL, 24.03.2011:19)

En estos casos, se considera la cláusula como no marcado debido a que no se aplican desplazamientos sintácticos, sino más bien estrategias referenciales catafóricas: se posterga la identidad del participante en función de Sujeto/ Meta para revelarlo posteriormente en el cuerpo de la noticia.

Los Temas no marcados se limitan a las opciones de Sujeto o Predicador en los títulos de La Nación. Sin embargo, en La Prensa Libre y en La Extra se emplea una opción más: el Complemento realizado por pronombre átono, el cual estuvo presente en cinco ejemplos de $L a$ Prensa Libre y de La Extra:

(25) Lo mató de una puñalada por una piedra de crack (LPL, 31.03.2011:17) 
(26) Lo cazan tras limpiar el Palí (LE, 3.03.2011: 9).

(27) Lo aniquilan con punzón por ф 10 mil (LE, 15.03.2011: 10)

Los ejemplos (25), (26) y (27) han sido clasificados como no marcados dentro del sistema TEMA, aunque sí en el sistema de la
INFORMACIÓN ${ }^{4}$ : utilizar un pronombre átono que hace referencia a un elemento aún por definir permite postergar su identidad, toda vez que la dependencia fonológica del pronombre hace que la atención del interlocutor recaiga en el verbo.

Los temas marcados presentan la siguiente distribución:

Gráfico 2 .

Temas marcados en la sección Sucesos de La Nación, La Prensa Libre y La Extra.

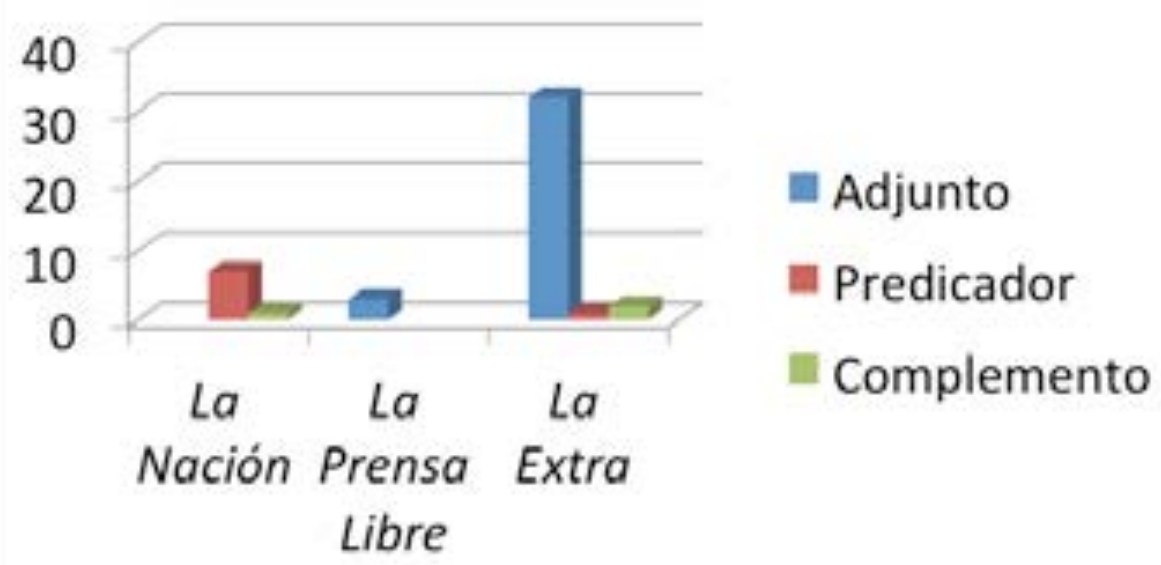

Estos resultados revelan que el uso de Temas marcados es muy reducido tanto en $L a$ Nación (con 8 ejemplos) como en La Prensa Libre (con 3 ejemplos). En este punto, destaca el hecho de que, a pasar de que el Adjunto es el Tema marcado que tiende a aparecer con mayor frecuencia, estuvo ausente en el corpus de $L a$ Nación, pues los casos que se registraron fueron, o bien Predicadores en cláusulas receptivas con Sujeto pospuesto (en 7 títulos), o bien Complemento realizado por grupo nominal (en un caso):

(28) Detenido violador en Goicoechea (LN, 11.03.2011: 18A)
(29) Liberado presidente municipal de Golfito (LN, 19.03.2011: 18A)

(30) Decomisadas 450 unidades de licor adulterado (LN, 24.03.2011: 18A)

(31) Arrestados peones por matar a ingeniero en robo de bicicleta (LN, 26.03.2011: 16A)

En todos los casos anteriores, el procedimiento es similar: se ha elegido una cláusula receptiva, cuya estructura no marcada implica el desplazamiento del Participante que cumple la función de Meta (el cual, en español, se desempeña sintácticamente como CD) para ocupar el lugar del Sujeto, hecho que involucra modificaciones en el grupo verbal al requerirse 
la incorporación del Finito ser más el participio del Predicador. Es decir, si la forma operativa para un ejemplo como (28) fuera policía detuvo violador en Goicoechea, su forma receptiva no marcada sería:

Tabla 1.

Cláusula material transitiva receptiva con el Proceso realizado por un grupo verbal pasivo, basado en Halliday (2004: 182).

\begin{tabular}{llcl}
\hline Violador & fue & Detenido & en Goicoechea \\
\hline Meta & Proceso: pasivo & Circunstancial \\
\hline Sujeto & Finito & Predicador & Adjunto \\
\hline Tema & \multicolumn{4}{c}{ Rema } \\
\hline
\end{tabular}

Sin embargo, se ha optado por iniciar la cláusula con el Predicador para lograr así encabezar el enunciado a partir de lo ocurrido, asignar a la Meta el estatus novedoso y restar importancia al Actor (el cual no aparece en ninguno de los ejemplos registrados).

El título que presentó el Complemento realizado por grupo nominal como punto de partida fue el siguiente:

(32) Cráneo, brazos y restos de ropa hallan en Upala (LN, 3.03.2011: 17A)

El verbo hallar tiende a ser utilizado en la sección de Sucesos en construcciones impersonales con Sujeto tácito de interpretación inespecífica, las cuales propician la introducción del enunciado a partir del Predicador y, a continuación, se coloca aquello considerado como novedoso. No obstante, en el ejemplo (32), se ha optado por un Tema con función sintáctica de Complemento, realizado por un grupo nominal, para así enfatizar la información que tenga el potencial de interpretarse como más controversial e impactante.

En La Prensa Libre, los tres Temas marcados presentaron la selección de un Adjunto como elemento inicial de la cláusula. Un ejemplo es el siguiente:

(33) Chapeando finca se corta arteria y muere (LPL, 29.03.2011:18)
El punto de partida de (33) es un Adjunto de modo, el cual, por medio del uso del gerundio, aporta movimiento y acción dentro del Tema y, al mismo tiempo, permite describir la manera en que sucedieron los hechos.

El recurso marcado más utilizado en $L a$ Extra es el Adjunto, el cual se utilizó en 32 ocasiones, y es una selección aplicable cuando se desea enfatizar algún aspecto ocurrido en torno al Predicador que particulariza la noticia y le confiere novedad y singularidad:

(34) Huyendo de balacera muere frente a su casa (LE, 29.03.2011: 7)

(35) Por planchar la oreja terminó en un charral (LE, 16.03.2011: 10)

(36) A cachete están los privados de libertad (LE, 11.03.2011: 13)

(37) En tetas llevaba crack a la cárcel (LE, 10.03.2011: 8)

En el título (34), se organiza el enunciado a partir de un gerundio, forma cuyo uso principal es referirse a acontecimientos que se encuentran en progreso. Este Adjunto presenta una acción que estaba teniendo lugar -huir-, pero que fue interrumpida por otra -morir-. Su selección como Tema favorece la presentación de los eventos de una manera más ágil y dinámica y crea un escenario de suspenso, puesto que su 
combinación con el sustantivo balacera lleva a la representación, por medio del lenguaje, de una situación de riesgo que podría despertar la intriga en el lector e incentivarlo a la lectura para conocer los detalles del acaecimiento.

El empleo de Adjuntos como Tema en los titulares puede dar al enunciado mayor relevancia y originalidad. Así, el ejemplo (35) posee una configuración ideacional con un solo un Participante -entidad deducible por la conjugación verbal- que ejecuta la acción codificada en el Proceso intransitivo terminar, utilizado con la acepción de dirigirse a otro lugar inesperadamente. Estos devenires primarios, que han alcanzado el estatus de noticia, se particularizan con la frase preposicional por planchar la oreja (que significa por quedarse dormido), que indica las razones por cuales ocurrió el percance. Este Adjunto inicial no solo logra conferirle a la cláusula notabilidad por su estatus anecdótico, sino que, al hacerlo por medio de una expresión popular, construye un efecto de complicidad con el lector que da como resultado la inclinación hacia el humor. Ya Sunkel (2002: 102) había distinguido este recurso como elemento diferenciador entre la prensa de "clases populares" y la de referencia, pues mientras que la segunda destaca por su seriedad, en la primera la jocosidad cumple la función de acercar al lector a ese mundo que se le describe para lograr que se identifique con él a través de los códigos compartidos. Entonces, en el titular (35), el Tema propicia la empatía, ya que es normal, para cualquier ser humano, sentirse cansado en un momento determinado $\mathrm{y}$, por ende, intentar tomar una siesta -o sea, planchar la oreja, haciendo propias las selecciones léxicas que el diario ha proferido-, por cuanto el Rema resulta ser la parte de la cláusula que transmite un final inesperado, tipo de cierre que coincide con el de las narraciones humorísticas, como en el caso de los chistes.

En el titular (36) $-A$ cachete están los privados de libertad (LE, 11.03.2011: 13)-, también se utiliza como Tema marcado un Adjunto que sobresale por la expresión popular que lo constituye. La frase preposicional $a$ cachete se encontraba en pleno apogeo en el momento de la publicación de la noticia y proviene del registro informal. Esta expresión se origina tomando como base una metáfora gastronómica: el placer que produce el ingerir los alimentos, deleite que se alcanza cuando las papilas gustativas entran en contacto con el manjar. En ese instante, la comida se halla dentro de la boca $\mathrm{y}$, consecuentemente, las mejillas resaltan. Cabe señalar que la expresión original completa es a cachete inflado, la cual remite directamente al período en el que la comida se encuentra dentro de la boca. Posteriormente, la expresión se redujo y dio como resultado aquella que se ha incorporado en (36), pero siempre denotando un hecho positivo, agradable, e incluso también existe su versión contraria: a cachete desinflado, que evoca una situación negativa. Entonces, el ejemplo (36) transmite información con respecto a las buenas condiciones en las que viven los privados de libertad, pero, para hacerlo, se vale de un Tema marcado que busca establecer una cercanía con el lector a través del uso de expresiones propias del sociolecto popular costarricense.

Finalmente, en el titular (37) -En tetas llevaba crack a la cárcel (LE, 10.03.2011: 8)- se favorece la organización del enunciado a partir del Adjunto por ser el aspecto más polémico del acontecimiento. Este ejemplo se estructura a partir de lo que se ha considerado como llamativo y se ha preferido el empleo del término tetas frente a eufemismos como senos o pechos para intensificar el impacto que se pueda crear en el lector a partir del uso de vocabulario más directo y sin reservas.

Los otros tipos de Temas marcados que se registraron en La Extra fueron dos ejemplos con Complemento como punto de partida y uno con Predicador, los cuales se muestran a continuación:

(38) A menor lo mató la policía tras asalto (LE, 17.03.2011: 9)

(39) A empresario porno le decomisan carro (LE, 25.03.2011: 9)

(40) Fue Absuelto alcalde de Oreamuno (LE, 22.03.2011: 12) 
Los titulares (38) y (39) presentan un Complemento como Tema, pues se ha considerado que dichos elementos resultan socialmente polémicos. De este modo, en el ejemplo (38) se codifica el evento a partir de lo sucedido a un menor de edad, quien, a pesar de su juventud, ya se había convertido en criminal, mientras que, en el titular (39), el aspecto más pintoresco es el Complemento, pues especifica una ocupación: empresario porno, y lo controversial de este trabajo le confiere la suficiente prominencia como para seleccionarlo como punto de partida. Por último, en el ejemplo (40) se ha preferido utilizar una cláusula receptiva y encabezarla con el Finito (que funciona como Tema interpersonal al brindar el tiempo primario) más el Predicador absuelto (Tema tópico) para así mostrar, en primer lugar, los resultados de un juicio y, posteriormente, dar a conocer la identidad de aquel individuo que estaba siendo juzgado.

\section{Conclusiones}

En la sección Sucesos, el estilo de La Extra difiere considerablemente en relación con $L a$ Nación y La Prensa Libre. Esto es así por cuanto el contenido relacionado con crímenes y violencia es uno de los principales focos de interés de la prensa sensacionalista, característica que va en concordancia con el color rojo de los títulos y con las imágenes violentas que acompañan la noticia y que buscan generar un impacto en el lector. Bajo esta óptica, el titular se construye partiendo del aspecto más llamativo de la representación: el Predicador. En La Extra, los Predicadores como Temas no marcados llegaron a superar a aquellos organizados a partir del Sujeto, hecho que evidencia el objetivo primordial de hacer un énfasis en los aconteceres que puedan causar mayor asombro en el lector. Otras estrategias que destacan, para el caso de La Extra, son el uso de elisiones del Sujeto y de los pronombres átonos como primer elemento del enunciado, los cuales tienen el potencial de despertar la curiosidad del lector y estimularlo a la continuidad de la lectura (afirmación que se respalda por la ausencia de un antecedente explícito en el antetítulo). Además, en La Extra, los Temas marcados alcanzaron mayor frecuencia de uso y, de entre ellos, sobresalió el empleo de Adjuntos, que particularizan algún aspecto del acontecimiento y le otorgan matiz anecdótico.

En resumen, el tipo de diario y los objetivos comunicativos perfilan las selecciones sintácticas en cuanto a la organización de los Participantes, los Procesos y las Circunstancias dentro del título periodístico. La forma no marcada que se le asigna a la mayoría de los títulos de La Nación y en La Prensa Libre contribuye a crear un tipo de redacción seria y neutral, pues, como se afirma en Pinuer y Oteíza (2012: 45) la estructura no marcada (SVO) es "más fácil de procesar y está centrado al receptor" en tanto facilita el procesamiento de la información. Por su parte, en La Extra, se interactúa con la información ya que el orden marcado "se dirige al hablante que, como sabe lo que va a transmitir, puede seleccionar una alternativa al orden canónico para cumplir un fin comunicativo" (Pinuer y Oteíza 2012: 45). La posibilidad de fluctuar en cuanto a la perspectiva que se adopta para dar a conocer la noticia incrementa el atractivo de esta y la particulariza, lo cual va en concordancia con el objetivo periodístico del tipo de diario: informar y entretener.

\section{Notas}

1. El antetítulo del titular (16) es la hallaron a la orilla de un río, Pérez Zeledón, el cual tampoco porta información con respecto a quién cometió el asesinato.

2. Para el titular (18), el antetítulo es Upala. Este incorpora información con respecto al lugar en donde se están realizando las indagaciones, pero no se incluye el nombre de la institución que las está llevando a cabo.

3. El antetítulo del ejemplo (23) es Puntarenas y el (24) no tiene.

4. En estos ejemplos, los antetítulos son, para (25) Cieneguita, Limón, para (26) Guápiles y, para (27), en aparente asalto en Heredia centro, es decir, tampoco revelan el antecedente al que el pronombre átono hace referencia. 


\section{Bibliografía}

Cuvardic, Dorde y Ericka Vargas. 2010. "Recursos lingüísticos en la titulación periodística costarricense: el caso de $\mathrm{La}$ Nación y el diario La Extra". En Revista de Filología y Lingüística 36 (1): 207-232.

Franco, Antonio y Vanessa Casanova. 2006. "Tema, rema y focalización: del enunciado al texto. Análisis de títulos y leads de prensa". En Quórum Académico 3(2): $55-81$.

Guerrero, Susana. 2007. La creatividad en el lenguaje periodístico. Madrid: Cátedra.

Gutiérrez-Ordóñez, Salvador. 2000. Temas, remas, focos, tópicos y comentarios. Madrid: Arco.

Halliday, M.A.K. 2004. An Introduction to Functional Grammar. Londres: Hodder Arnold.

Halliday, M.A.K. 1986. El lenguaje como semiótica social. La interpretación social del lenguaje y del significado. México D.F.: Fondo de Cultura Económica.

Hernando, Luis Alberto. 2000. Discurso periodístico. Madrid: Editorial Verbum.

Jakobson, Roman. 1984. "Lingüística y poética". En Ensayos de lingüistica general. Barcelona: Ariel.

Lakoff, G., Johnson, M. 2003. Metaphors we live by. Londres: University of Chicago Press.
Nadal, Juan. 2008. "Verdades a medias: la nominalización deverbal en los titulares periodísticos". En Comunicación $y$ Sociedad (9): 175-185.

Núñez-Ladeveze, Luis. 1979. El lenguaje de los "media”. Madrid: Pirámide.

Pinuer, Claudio y Teresa Oteíza. 2012. "Principios, competencia y anulamientos en el orden de los constituyentes oracionales". En Signos 45(78): 83-99.

Real Academia Española (RAE). 2010. Manual de la nueva gramática de la lengua española. México D.F.: Editorial Planeta Mexicana.

Samiolo, S. 2008. Semantic Styles in the British Daily Press: a corpus study. Tesi di dottorato in Scienze Linguistiche, Filologiche e Letterarie: Università degli Studi di Padova.

Sánchez-Sánchez, José Francisco. 1990. “Títulos y Titulares. Sobre las funciones de la titulación periodística". En Comunicación y Sociedad 3(1 y 2): 173-183.

Sunkel, Guillermo. 2002. La prensa sensacionalista y los sectores populares. Bogotá: Editorial Norma.

Van Dijk, Teun. 1996. La noticia como discurso. Barcelona: Paidós.

Vargas, Ericka. 2015. "Las funciones del lenguaje de Jakobson en la titulación deportiva: estudio estilístico de La Nación y La Extra". En Revista de Filología y Lingüistica de la Universidad de Costa Rica 41(1): 143-156.

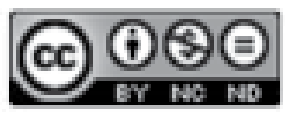

Este obra está bajo una licencia de Creative Commons

Reconocimiento-NoComercial-SinObraDerivada 4.0 Internacional. 
